\title{
Assessment of Post Graduate Medical Students in Nepal: Is it time to introspect?
}

\author{
Shrestha D, Shrestha R
}

Department of Orthopedics and Traumatology

Dhulikhel Hospital, Kathmandu University Hospital

Dhulikhel,Kavre, Nepal

Post graduate medical education was started in Nepal in 1982 in General Practice and in Ophthalmology in 1987 by Institute of Medicine (IOM), Tribhuvan University (TU). Kathmandu University (KU) started its first postgraduate program in Orthopaedics in 1999. BP Koirala Institute of Health Sciences (BPKIHS) and National Academy of Medical Sciences (NAMS) started in 1999 and in 2003 respectively. Before NAMS, Post Graduate Medical Education Co-ordination (PGMECC) was responsible for post graduate programme. ${ }^{1}$ Nepal Medical Council (NMC) being regulatory body for both undergraduate and post graduate medical education, regulates medical program in Nepal. However, NMC is so far not able to provide adequate attention in assessment system of post graduate medical students. With changing trends of education system as well as expanded area of medical and surgical technologies, conventional techniques of assessing post graduate students need to be revised and reconsidered.

Assessment of post graduate students for competence and performance directly or indirectly influence in ability to work as an independent physician or teacher in future. Conventionally, all medical schools that are running post graduate medical education in Nepal have followed or adopted assessment system of our neighboring country India. This system has two components; theoretical assessment in the form of written examinations with four theory papers and clinical/practical and oral examinations which include one long case and two short cases. ${ }^{2}$ But this traditional systems of assessment of student have many unexplored areas. Some of the pertaining issues are:

- Does the current system of evaluation assess postgraduate students comprehensively?

- Should there be any contribution of midterm assessment or evaluation of students?

- How to assess psychomotor skills of the candidate? In the current assessment system, there are no provisions of evaluation of performance/practical skill such as application of cast or emergency appendectomy or anterior nasal packing or counselling of patient.

- What should be minimum criteria to label candidates unsuccessful? There are different cut off values or criteria in different institution or universities in Nepal. Do minimum criteria of failing students affect competence and performance of post graduate students?

- Is it a time to consider creating a common exit examination board for all universities or institutions? There are some difference in training manuals and system of post graduate training in different universities or institution in Nepal. For example: in BPKIHS, post graduate students have to spend two weeks/year in periphery or district or regional hospitals. General surgery residents in BPKIHS are posted in anesthesia for four weeks unlike in TU or KU where general surgery residents are posted for six weeks in orthopedics. None of the residents under KU or TU or NAMS need rural area posting which is actually recommended in some of the universities and considered to add on the candidates' ability to adapt and perform better once they practice in real world. Microteaching skills, which are emphasized and assessed for basic science post graduate students, do not get adequate priority in clinical subjects in $\mathrm{KU}$. With these differences in training manual in different institution and universities within country, to design and develop a common exit examination board for all post graduate students in Nepal can be challenging. However, a common exit examination board can be a one of the solution to maintain uniform standard of postgraduate doctors within country.

- What should be the contribution of thesis or dissertation work in final assessment of post graduate students? Post graduate candidates are not eligible for final assessment unless thesis works is completed. But there is no mandatory provision to defend or present thesis work to the examiners. There is again discrepancy on system of evaluation of thesis work in different universities and institutions. For example, in ophthalmology in Institute of Medicine (IOM), there is a separate day for evaluation of thesis work but not in other subjects. 
- In theory papers, question pattern are not uniform and there are no guidelines in designing questions. Unlike in undergraduate programme, very little attention has been given in training question setters for post graduate examination and as a result, assessment of post graduate students in different domains could not be achieved as per demand of standard practice of modern medicine. Department of Radiodiagnosis, Orthoapedics and Paediatrics in IOM conduct basic science theory paper in first year and other two papers in final year where as in other departments in IOM, KU, NAMS and BPKIHS, all three theory papers are conducted in final year.

Therefore, it is now time to introspect our system of assessment of post graduate medical students. Examiner should get enough time to assess the candidates for not only skill and knowledge of subjects itself but also evaluate attitude, values and ethics of the candidates towards patients, colleagues and students. Besides theory papers and clinical examination session, simulation exercises should be incorporated in examination. Universities, institution, specialty boards and professional association and NMC should play important role in redesigning of current assessment system of post graduate medical students in Nepal because future health of Nepalese people; future of medical education in Nepal and future of research in medical field depends upon competence and confidence of post graduate doctors and these capacities are assessed during their post graduate examination.

\section{REFERENCES}

1. Karki DB, H Dixit. An overview of undergraduate and postgraduate medical education in Nepal and elsewhere. Kathmandu Univ Med J. 2004; 2(1): 69-74.

2. http://www.mciindia.org/Rules-and-Regulation/Postgraduate-Medical-Education-Regulations-2000.pdf. pp.23-24 